\title{
Application of flow cytometry to determine the cytotoxicity of urethane dimethacrylate in human cells
}

\author{
M. Reza Nassiri, ${ }^{1, *}$ Carl T. Hanks, ${ }^{2}$ Mark J. Cameron, ${ }^{1}$ Susan E. Strawn, ${ }^{2}$ and Robert G. Craig ${ }^{1}$ \\ ${ }^{1}$ Department of Biologic and Materials Sciences and ${ }^{2}$ Department of Pathology and Oral Surgery, School of Dentistry, \\ The University of Michigan, Ann Arbor, Michigan 48109-1078
}

The effects of an oligomer, urethane dimethacrylate (UDMA), on two human cell lines were studied using flow cytometry (FCM). Untreated and treated cultures of propidium iodine-stained KB (epidermal oral carcinoma cells) and human foreskin fibroblast (HFF) cells were analyzed for cellular DNA content. Concentrations of 10 and $25 \mu \mathrm{M}$ of UDMA slightly perturbed the KB cell cycle progression at 24 and 48 h of incubation. However, the effect of $50 \mu \mathrm{M}$ was more pronounced at the latter incubation time period. In cell growth experiments, the sublethal concentrations (10 and $25 \mu \mathrm{M})$ produced inhibition of $\mathrm{KB}$ cell growth rate at a moderate level, which resulted in the prolongation of cell population doubling time. Significant inhibition of cell growth occurred when $50 \mu \mathrm{M}$ (lethal concentration) was used. Data obtained from the cell cycle perturbation analysis, evidenced by FCM, correlated with the extent of inhibition in $\mathrm{KB}$ cell growth rates. The effects of sublethal concentrations were reversible during a $24 \mathrm{~h}$ period of oligomer withdrawal from culture medium. In contrast, the effects of $50 \mu \mathrm{M}$ were not reversible. In HFF cells the depletion of $S$ phase in the cell cycle was the major effect of $50 \mu \mathrm{M}$ of UDMA. It was concluded that FCM technology is an ideal and practical approach for studying the cytotoxicity of components of dental composites. (C) 1994 John Wiley \& Sons, Inc.

\section{INTRODUCTION}

With the increasing concern over the biocompatibility of synthetic materials, and a search for more reliable and reproducible in vitro models to measure the cytotoxicity of such materials, flow cytometry (FCM) has been used to determine cytotoxic effects of a resin component, UDMA, on cell cycle distribution. Currently, in vitro screening methods for testing cytotoxicity of biomedical materials, including dental materials, include morphologic effects on cell test systems, or at a functional level, effects on enzyme systems or cell membrane integrity. ${ }^{1-6}$ Thus, the agar overlay test and the chromium release tests for membrane permeability and the molecular filter test using enzyme histochemistry for succinic dehydrogenase activity are acceptable to the International Standards Organization. ${ }^{7}$ The agar overlay test (F895-84) and the direct contact test, which demonstrate changes in cell morphology (F895-84), are ASTM standard methods. ${ }^{8}$ Only the chromium release assay method is listed at present as a suggested method for cytotoxicity testing by the ANSI/ADA Document 41, revision $1982 .{ }^{9}$

*To whom correspondence should be addressed.
These documents and standards are being revised periodically.

There are many metabolic steps that could be evaluated as measures of cytotoxic effect of various materials and devices that come in contact with living tissue. Standard tests must be specific enough to measure effects that are vital to cell function, but yet general and simple enough to be easily reproducible in a number of laboratories. The repeatability of methods such as thymidine labeling may be difficult because the method is labor intensive and the results depend largely on an understanding of the dynamics of DNA synthesis in various cell lines. ${ }^{10-13,18}$ FCM is a method that is standardized and appropriate for materials testing. FCM methodology involves binding of dyes such as propidium iodine to DNA allowing the quantitation of DNA in each cell. In this study, FCM technology was used to study the cytotoxicity of a composite resin in vitro, using established human cell lines. More specifically, the cell cycle perturbations in $\mathrm{KB}$ and human foreskin fibroblast (HFF) cells were determined in cultures that were exposed to various concentrations of UDMA. The chemical structure of UDMA is shown in Figure 1. The incubations were 24 and $48 \mathrm{~h}$ in duration. To understand further the 
aberrations of the cell cycle phase assessed by FCM, the growth rates of $\mathrm{KB}$ cells exposed to the oligomer concentrations were also studied.

\section{MATERIALS AND METHODS}

\section{Dental composite}

UDMA was generously supplied by Esschem Company (Essington, PA). The oligomer was dissolved in 100\% DMSO (Fisher Scientific, Pittsburgh, PA), and then diluted in medium so that the final concentration of DMSO was $0.1 \%$. This concentration of DMSO had no effect on cell viability, as measured by trypan blue dye exclusion, or cell growth rates.

\section{Cells}

KB cells, an established human line derived from an epidermal oral carcinoma, were routinely grown in minimal essential medium (MEM) with Hanks' salt $[\mathrm{MEM}(\mathrm{H})]$ supplemented with 5\% fetal bovine serum. Cells were passaged by conventional procedures by using $0.05 \%$ trypsin and $0.02 \%$ EDTA in a HEPES (N-2-hydroxyethoxylpiperazine$\mathrm{N}$-2-ethanesulfonic acid)-buffered salt solution. ${ }^{14}$ Primary HFF was grown in minimal essential medium with Earle's salts (MEM[E]) supplemented with 10\% fetal bovine serum. To increase the likelihood of detecting bacterial or mixed bacterial and mycoplasma contamination, antibiotics were never used in the routine passage of both cells lines. ${ }^{15}$ Cells were screened periodically and were mycoplasma-free.

\section{Flow cytometry}

Untreated and oligomer-treated cultures of $\mathrm{KB}$ and HFF cells in six-well plates were harvested and resuspended in media. Aliquots of the cells were placed into test tubes at a concentration of $3.0 \times 10^{5}$ cells per milliliter. Chicken erythrocytes (Whittaker Bioproducts, Walkersville, MD) were added in amounts equal to $20 \%$ of the KB or HFF cells as internal biologic standards. Samples were centrifuged at $200 \times g$ for $5 \mathrm{~min}$. The supernatants were decanted and cell pellets were resuspended in PBS, gently vortexed, and washed twice. The staining solution (PI reagent) contained $0.01 \mathrm{M}$ Trisma base, $700 \mathrm{U} / \mathrm{L}$ RNase, $0.1 \%$ Nonidet P40 (NP40), $10 \mathrm{mM}$ sodium chloride, and $7.5 \times 10^{-5} \mathrm{M}$ propidium iodine. One milliliter of the PI reagent was added per test tube and vortexed gently. The resulting preparations were placed in ice water and incubated for $30 \mathrm{~min}$. After incubation, the nuclear suspensions were fixed by the addition of $100 \mu \mathrm{L}$ of $2 \%$ paraformaldehyde per test tube, vortexed, and stored in the dark at $4^{\circ} \mathrm{C}$ overnight until flow cytometric analysis. ${ }^{12}$

Propidium iodine (PI) stained cells were analyzed on an EPICS 751 flow cytometer (EPICS division, Coulter Corporation, Hialeah, FL) fitted with an argon laser emitting at $488 \mathrm{~nm}(200 \mathrm{~mW})$, and with a $488 \mathrm{~nm}$ laser-blocking filter, a long pass filter, a $560 \mathrm{~nm}$ dichroic filter, and a $630 \mathrm{~nm}$ long pass filter. Photomultiplier tube high voltage was adjusted to maintain the chick erythrocytes (CRBC) peak in channel 20. The CRBC also served as a threshold for acceptable fluorescence intensity. Events having less fluorescence than CRBC nuclei were considered debris. In all samples, a total of 10,000 nuclei were analyzed.

Data storage and analyses were performed using the Coutler EASY2 computer system. The estimated percentage of cells in $G_{0} / G_{1}, S$, and $G_{2} / M$ phases were obtained using the PARA1 option of the EASY2 software (Coulter Electronics, Hialeah, FL), originally described by Bagwell. ${ }^{17}$ Graphic presentation of histograms were made as described by Cameron. ${ }^{16}$ Briefly, histogram data were translated to a file format compatible with commonly available software. For histogram comparison, the CRBC peaks were translocated to channel 20. Average DNA histograms of treated cells were generated from three separate cultures compared with three cultures of respective untreated cells.

\section{Cell growth profile}

Six-well plastic tissue culture dishes or $25 \mathrm{~cm}^{2}$ flasks were used to study the inhibitory effect of UDMA on KB cell growth. After an incubation during which cells attached to the substrate, the medium was decanted, the cell sheet was rinsed once with HBS, and fresh medium was added. The medium consisted of $\mathrm{MEM}(\mathrm{H})$ with $0.7 \mathrm{mg} \mathrm{NaHCO}_{3} / \mathrm{L}$ and $5 \%$ fetal bovine or calf serum plus appropriate concentrations<smiles>C=C(C)C(=O)OCC(C)OC(=O)NCC(C)(C)CC(C)CCNC(=O)OC(C)COC(=O)C(C)(C)C</smiles>

Figure 1. Chemical structure of urethane dimethacrylate (UDMA). 
of UDMA. After additional periods of incubation from 24 to $72 \mathrm{~h}$ at $37^{\circ} \mathrm{C}$, cells were harvested by means of $0.05 \%$ trypsin plus $0.02 \%$ EDTA in a HEPES-buffered salt solution, $\mathrm{pH}=7.4$. Cells were enumerated using either a Coulter Counter or a hemocytometer. Viability was determined using trypan blue dye exclusion. ${ }^{2}$ Untreated cells throughout this study displayed $98-99 \%$ viability.

The population doubling time (PDT) for $\mathrm{KB}$ cells growing in the presence or absence of UDMA was subsequently calculated from the data using the subsequent equation:

$$
\mathrm{PDT}=0.301(t) /(\log I)-(\log F)
$$

where $I$ is equal to the total cell number in each well at the time when various concentrations of UDMA were added (time 0 ), $F$ is equal to the average of triplicate wells after growing $48 \mathrm{~h}$ in the presence or absence of UDMA, and $t$ is equal to the elapsed time (in this case, 48 h). ${ }^{19}$

Dose-response relationships were constructed by linearly regressing the percentage of inhibition of parameters derived in the preceding sections against oligomer concentrations. The $50 \%$ inhibitory $\left(\mathrm{I}_{50}\right)$ concentrations were calculated from the regression lines. ${ }^{20}$

\section{RESULTS}

\section{Perturbations in cell cycle progression}

The effects of UDMA on the cell cycle distribution of human cells were analyzed by FCM of PI-stained cells. The flow histograms illustrating the kinetic of cellular responses of KB cells are shown in Figure 2. Concentrations of $10 \mu \mathrm{M}$ UDMA slightly perturbed the progression of cell cycle. A slight decrease $(2 \%)$ in the population of cells in $\mathrm{G}_{2} / \mathrm{M}$ phase was noted by $24 \mathrm{~h}$ of incubation. However, the effect at $48 \mathrm{~h}$ was more pronounced, resulting in the accumulation of cells in the $S$ and $G_{2} / M$ phases. When $25 \mu \mathrm{M}$ was used for $24 \mathrm{~h}$, the population of treated cells contained fewer cells in $S$ and $G_{2} / M$ phases when compared with untreated cells. Similar results were obtained after $48 \mathrm{~h}$ of incubation. The cell cycle effect at $50 \mu \mathrm{M}$ concentration was more pronounced, resulting in significant depletion of cells from $G_{0} / G_{1}$ phase. In contrast, the results were different when HFF cell cultures were exposed to the same concentration of oligomer. At $24 \mathrm{~h}$, more cells $(11 \%)$ were accumulated throughout the $G_{0} / G_{1}$ phase. However, when the incubation was carried to $48 \mathrm{~h}$, there was a significant depletion of cells $(24 \%)$ with S phase when compared with untreated HFF cells (Fig. 3).

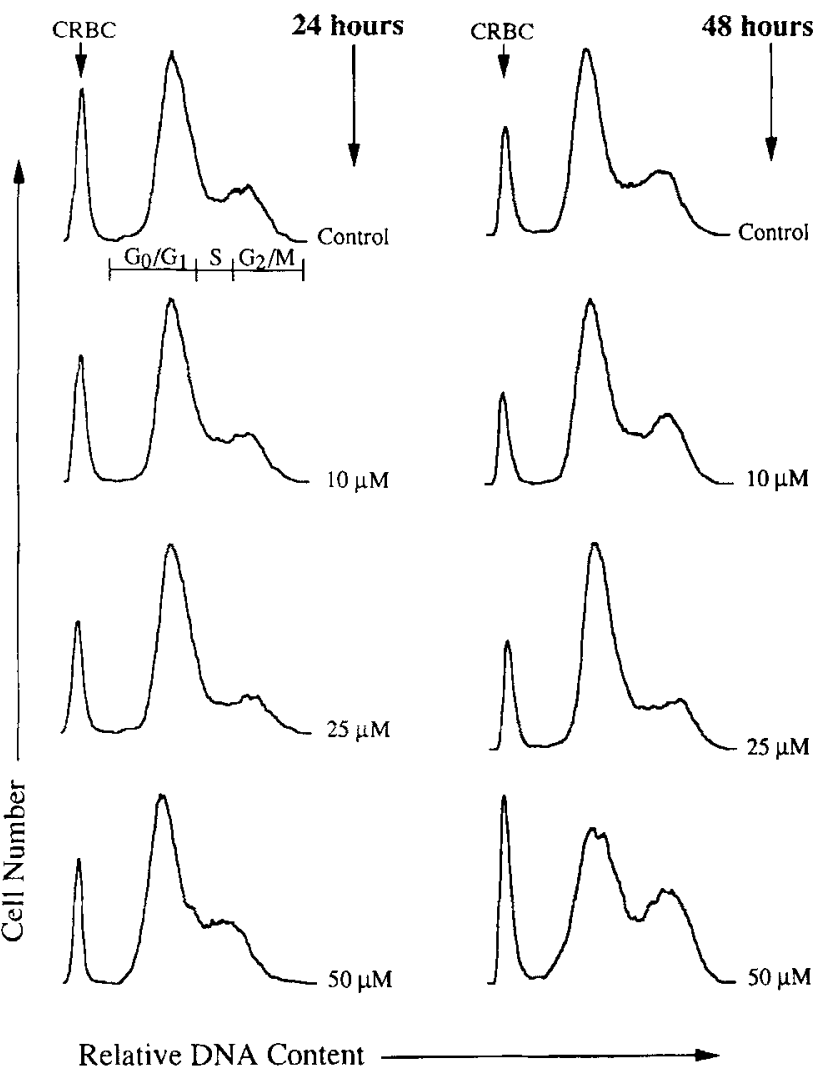

Figure 2. Distribution of DNA content frequency histogram following a kinetic response of $K B$ cells to 10, 25, and $50 \mu \mathrm{M}$ of UDMA after 24 and $48 \mathrm{~h}$ exposure times. Coefficients of variations of the $G_{1}$ peak were typically in the range of $4-5 \%$ for control cells.

\section{Inhibition of cell growth rate}

Exponentially growing cultures of $\mathrm{KB}$ cells were treated with different concentrations of UDMA for 24 and $48 \mathrm{~h}$. Figure 4 shows the effect of three concentrations of UDMA in $0.1 \%$ DMSO and medium on the number of cells per well after $48 \mathrm{~h}$. At a concentration of $10 \mu \mathrm{M}$, the inhibitions of cell growth were 21 and $34 \%$ of control after 24 and $48 \mathrm{~h}$, respectively. Cell growth suppression was significantly greater when $25 \mu \mathrm{M}$ was used. A $63 \%$ growth inhibition was noted by $48 \mathrm{~h}$. However, at shorter exposure times $(24 \mathrm{~h})$, the inhibition of cell growth was $52 \%$. When $50 \mu \mathrm{M}$ of UDMA was used, significant inhibition $(91 \%)$ of cell proliferation occurred after $48 \mathrm{~h}$, as compared with $74 \%$ inhibition of cell growth at $24 \mathrm{~h}$. The total number of cells dramatically declined when compared with the point at which UDMA was added. Increasing concentrations of UDMA also produced a longer PDT (Table I). I $_{50}$ concentrations were calculated for the exposure times indicated. ${ }_{50}$ 's equal to 23 and $6.2 \mu \mathrm{M}$ were obtained for 24 and $48 \mathrm{~h}$ of incubation, respectively (data not shown), suggesting that the growth effects were not only concentration-dependent, but also time-dependent. 


\section{Reversibility of growth inhibition}

In an attempt to determine whether the suppression of $\mathrm{KB}$ cell proliferation seen in Figure 4 was transient, a separate experiment was performed using the identical concentrations of UDMA used in the cell growth studies. The oligomer was removed from the cell cultures after a $24 \mathrm{~h}$ incubation (Fig. 5). After the removal, the $\mathrm{KB}$ cell growth resumed for those cultures that had been exposed to 10 and $25 \mu \mathrm{M}$ UDMA. The PDT for the recovery period for $10 \mu \mathrm{M}$ UDMA was the same as that for the controls. For $25 \mu \mathrm{M}$ UDMA-treated cultures, the PDT was somewhat longer during the recovery period. However, growth recovery sharply declined in cultures that had been treated with $50 \mu \mathrm{M}$ UDMA. This observation indicates an irreversible inhibition by $50 \mu \mathrm{M}$ UDMA, a dose that was lethal to the cells so that they were no longer capable of surviving.

\section{DISCUSSION}

Exposure of $\mathrm{KB}$ cell cultures to various concentrations of UDMA for two different incubation times resulted in a different set of events that led to the classification of the concentrations as sublethal (10 and $25 \mu \mathrm{M})$, and lethal $(50 \mu \mathrm{M})$. As shown in Figure 2, considerable cell loss was associated with the $G_{1} / G_{0}$ phase at $48 \mathrm{~h}$ when $50 \mu \mathrm{M}$ of UDMA was used. This loss is probably due to a retarded rate of cell entry from $S$ into the $G_{2} / M$ phase, in which the progression of cells was markedly blocked. Therefore, fewer cells recycled in the next $G_{0} / G_{1}$ phase (inhibition of mitosis). In a recent study, Zucker et al. identified similar cell cycle perturbation events after the exposure of murine erythroleukemic cells to methylmercury. ${ }^{21}$ To follow up this particular finding in $\mathrm{KB}$ cells, experiments on the reversal of cell growth were conducted and confirmed that the cytometric aberration seen at this level of the cell cycle was a reflection of irreversible metabolic phenomena eventually leading to in vitro cell death. However, it is not understood whether such effects associated with the lethal concentration have biologic relevance in vivo. Moreover, the absence of an immune response in this in vitro system is another variation from the in vivo conditions. Certainly, animal experiments are needed to confirm the dose that results in demonstrable cell death and/or tissue necrosis in vivo. The mechanisms of action of UDMA and the basis of its selectivity for $S$ and $\mathrm{G} 2 / \mathrm{M}$ phases in $\mathrm{KB}$ cells, as well as its selectivity for $S$ phase in HFF cells remains unclear. However, the changes in the frequency of distribution of DNA content at lethal dose appear to be limited to a postDNA synthetic event. The lower concentrations of UDMA produced minor cell cycle perturbations that

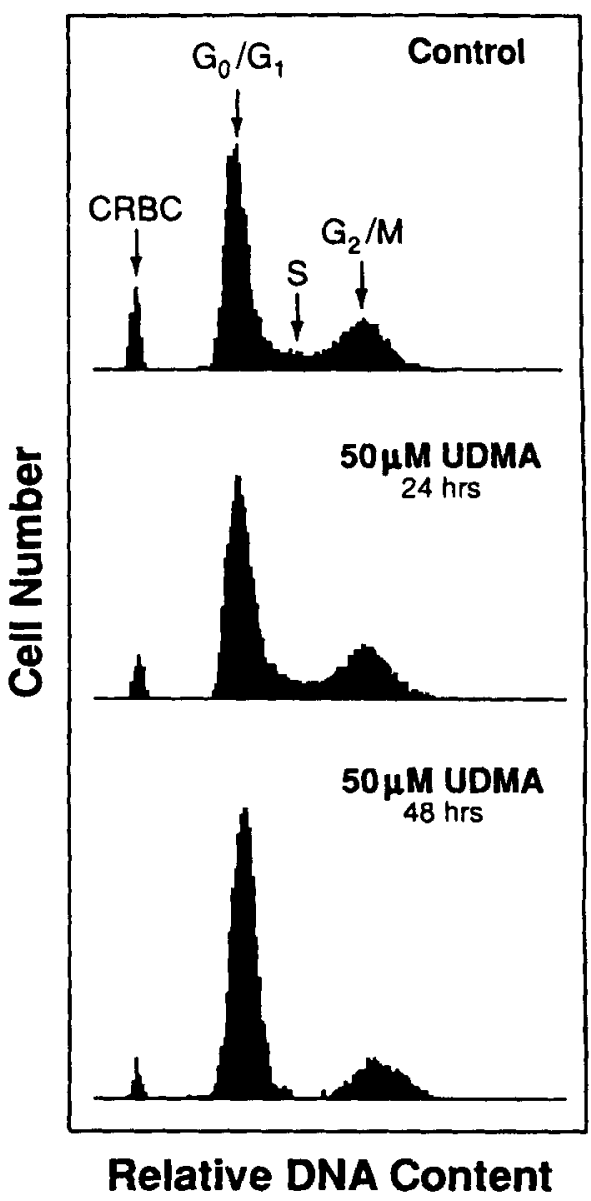

Figure 3. DNA content frequency histograms of HFF cells treated with $50 \mu \mathrm{M}$ UDMA for 24 and $48 \mathrm{~h}$. Significant depletion of the $S$ phase cell population was observed at $48 \mathrm{~h}$ of incubation. Coefficients of variations of the $G_{1}$ peak were typically in the range of $3-4 \%$ for control cells.

were only cytostatic in $\mathrm{KB}$ cells, as confirmed by the reversal experiments. This suggests that the oligomer may affect cellular DNA polymerase rather than act as an irreversible chain terminator. The major cellular effects of the sublethal concentrations of UDMA appeared to be: 1) existence of fewer cells in $\mathrm{G}_{2} / \mathrm{M}$ phase as compared with the untreated cultures, and 2) prolonged PDT.

After exposure of L929 cells to Doxorubicin, Lanks et al. ${ }^{22}$ showed that there was no correlation of drug effects between DNA-FCM and a colonigenic survival assay. This suggests that there were differences in sensitivities of the colony assay and the FCM analysis. However, in the present study, there was good agreement between FCM and inhibition of KB cell growth rates. The cell cycling and cell growth effects of UDMA were dependent on both dose and time of exposure. Because of the significant cell cycle aberrations seen in the $\mathrm{KB}$ cells at $50 \mu \mathrm{M}$ of the oligomer, we have further expanded this study and have used human diploid HFF cells to evaluate the 


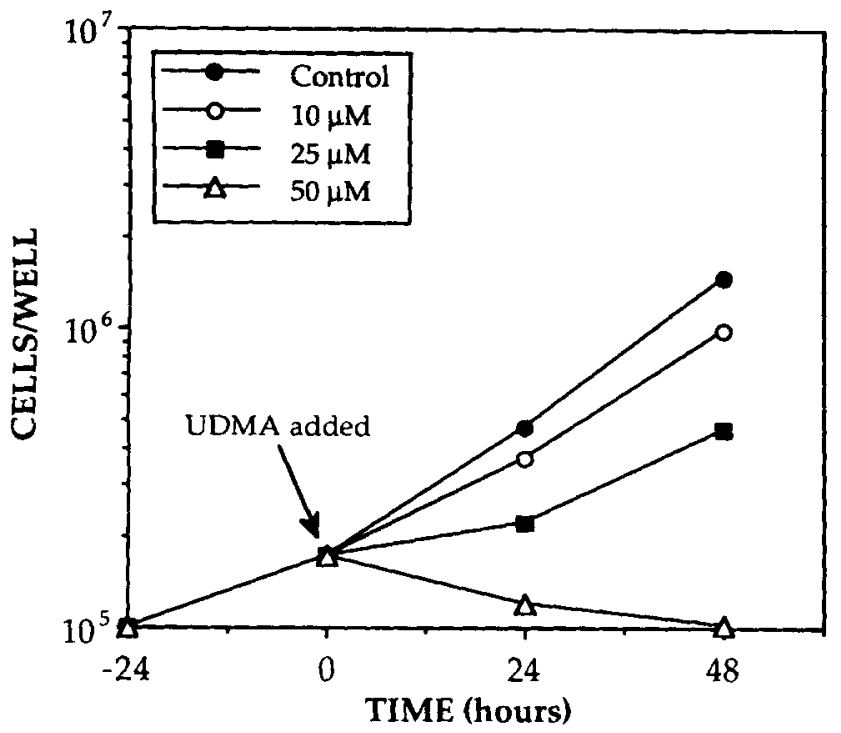

Figure 4. Effects of UDMA on growth of $\mathrm{KB}$ cells. Cells were seeded at 100,000 cells per well in six-well cluster dishes and incubated for approximately $24 \mathrm{~h}$. At time intervals indicated, old medium was decanted and fresh medium containing selected concentrations of UDMA were added. At subsequent times, cells were harvested and enumerated with a Coulter Counter. Each data point represents the average of triplicate cultures.

cell cycle effects of UDMA. The results showed that, although the progression of HFF cell cycle was also affected by $50 \mu \mathrm{M}$ of UDMA, the phase selectivity was different from that observed in $\mathrm{KB}$ cells. This suggests that differential cell type sensitivity may exist when the cytotoxicity of biomaterials is tested in tissue cultures. Overall, these data indicate that the delay in cell cycle progression of both KB and HFF cells by UDMA is a function of cellular DNA integrity.

The application of FCM technology has been widely and successfully used in various fields of clinical medicine and basic science research, particularly in diagnostic pathology and cancer and antiviral research to monitor the ploidy of tumor cells, and to determine the cytotoxicity of antineoplastic or antiviral agents. ${ }^{23-26}$ To expand further the application of this technology, it is proposed that the technology is useful in the study of the cytotoxicity of biomaterials, such as resins used in biomedical fields.

In summary, it has been shown that the oligomer, UDMA, altered the distribution of the $\mathrm{KB}$ and HFF cell cycle as measured by FCM, and that it func-

TABLE I

Population Doubling Time (h) of KB Cells in the Presence and Absence of Increasing Concentrations of UDMA During $48 \mathrm{~h}$ of Exposure

\begin{tabular}{cccc}
\hline Untreated & $10 \mu \mathrm{M}$ & $25 \mu \mathrm{M}$ & $50 \mu \mathrm{M}$ \\
\hline $16.1 \pm 0.4^{*}$ & $19.3 \pm 0.4^{*}$ & $34.3 \pm 0.5^{*}$ & $>100$ \\
\hline
\end{tabular}

${ }^{*}$ Mean $\pm S D$. Results are the average of two separate experiments.

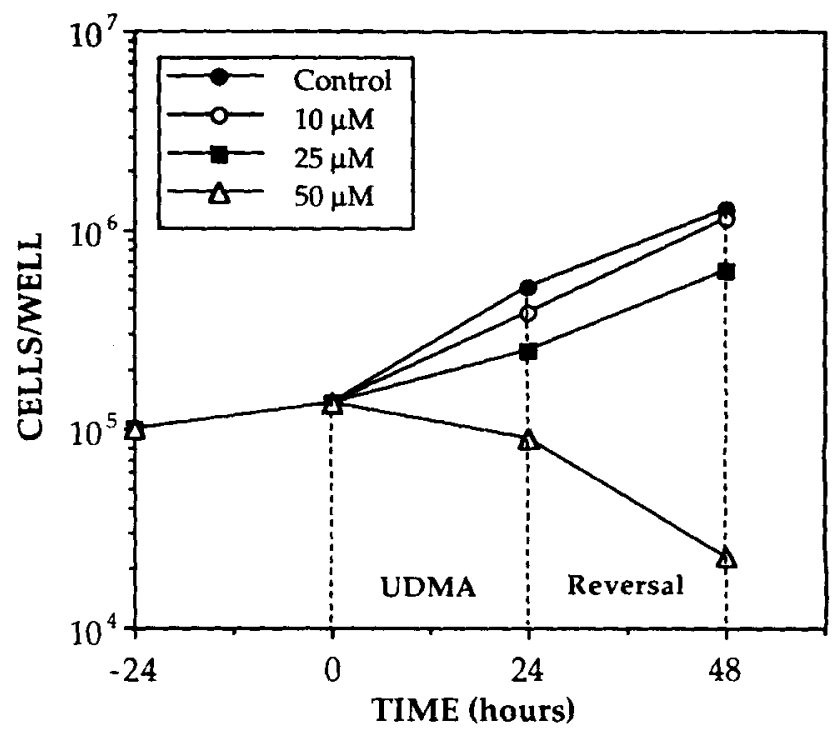

Figure 5. Reversibility of the inhibition of $\mathrm{KB}$ cell growth caused by UDMA. AT $24 \mathrm{~h}$ time intervals," various concentrations of UDMA were added and cells were incubated for another $24 \mathrm{~h}$. After the second time interval, UDMA-containing medium was removed from the cells and incubation was continued with UDMA-free medium. By the end of incubation period, cells in control wells plus wells from which UDMA was removed were harvested and enumerated with a Coulter Counter. Each data point represents the average of triplicate cultures.

tioned in both cytostatic and a cytotoxic manner in $\mathrm{KB}$ cell cultures, depending on the concentrations of the oligomer. The extent of cellular damage was related to the duration of exposure. A correlation emerged between the effects seen by FCM and the degree of cell inhibition. It was concluded that FCM assessment of cellular DNA content has been a substantial aid in assessing and monitoring the potentially cytotoxic responses of cultured cells to an oligomer component of resins, and that this technology offers an important tool for understanding the biocompatibility of dental and other biomedical materials.

This work was supported by funds from the National Institute for Dental Research, Grant P50-09296.

\section{References}

1. R. J. Craig and C. T. Hanks, "Reaction of fibroblasts to various dental casting alloys," J. Oral Path., 17, $341-347$ (1988).

2. A. McNamara and D.F. Williams, "Enzyme histochemistry of the tissue response to pure metal implants," J. Biomed. Mater. Res., 18, 185-206 (1984).

3. G. Schmalz, "Agar overlay method," Intern. Endodontic J., 21, 59-66 (1988).

4. L. Spangberg, "Kinetic and quantitative evaluation of material cytotoxicity in vitro," Oral Surg., 35, 389-401 (1973).

5. M.J. Tyas, "A method for the in vitro toxicity testing of dental restorative materials," J. Dent. Res., 56, 1285-1290 (1977). 
6. A. Wennberg, I. A. Major, and A. Hensten-Petterson, "Biological evaluation of dental restorative materials-a comparison of different test methods," J. Biomed. Mater. Res., 17, 23-26 (1983).

7. International Standards Organization Technical Report 7405-1984. Association for Advancement of Medical Instrumentation, Arlington, Virginia.

8. American Society for Testing and Materials (ASTM), F813-83 (reapproved 1988): Standard practice for direct contact cell culture evaluation of materials for medical devices. F895-84: Standard test method for agar diffusion cell culture screening for cytotoxicity, Philadelphia, 1990.

9. American National Standard/American Dental Association, Document no. 41 for recommended standard practices for the biological evaluation of dental materials. Council on Dental Materials, Instruments and Equipment, American Dental Association, Chicago, 1982, pp. 1-60.

10. H. R. Mauer, "Potential pitfalls of $\left[{ }^{3}-\mathrm{H}\right]$ thymidine techniques to measure cell proliferation," Cell Tissue Kinet., 14, 111-120 (1981).

11. C. A. Hoy, E.D. Lewis, and R. T. Schimke, "Perturbations of DNA replication and cell cycle progression by commonly used $\left[{ }^{3}-\mathrm{H}\right]$ thymidine labeling protocols," Mol. Cell. Biol., 10, 1584-1592 (1990).

12. M. R. Nassiri, J. L. Hudson, J.S. Pudlo, G. M. Birch, L. B. Townsend, and J.C. Drach "Flow cytometric evaluation of the cytotoxity of novel antiviral compounds," Cytometry, 11, 411-417 (1990).

13. K. Pollak, H. Moulis, D.B. Greenstein, N.L. Block, and G.L. Irvin III, "Cell kinetic effects of incorporated ${ }^{3} \mathrm{H}$-thymidine on proliferating human lymphocytes: Flow cytometric analysis using the DNA/nuclear protein method," Cytometry, 6, 428-436 (1985).

14. C. Shipman, Jr., "Evaluation of 4-(2-hydroxyethyl1-piperazineëthanesulfonic acid (HEPES) as a tissue culture buffer," Proc. Soc. Exp. Biol. Med., 130, 305-310 (1969).

15. L. Hayflick "Screening tissue cultures for mycoplasma infections," in Tissue Culture: Methods and Application, P.F. Kruse, Jr., and M.K. Patternson, Jr. (eds.), Academic Press, Inc., New York, 1973, pp. $722-728$.
16. M.J. Cameron, "Macintosh graphics for the EPICS flow cytometer user," Cytometry, 11, 916-918 (1990).

17. C. B. Bagwell, "Theory and application of DNA histogram analysis," Ph.D. thesis. University of Miami, Coral Gables, Florida, 1979.

18. H. P. Beck, "Radiotoxicity of incorporated $\left[{ }^{3} \mathrm{H}\right]-$ thymidine as studied by autoradiography and flow cytometry," Cell Tissue Kinet., 12, 163-177 (1981).

19. M. N. Prichard, L. E. Prichard, W. A. Baguley, M. R. Nassiri, and C. Shipman, Jr., "Three-dimensional analysis of the synergistic cytotoxicity of ganciclovir and zidouvudine," Antimicrob. Agents Chemother., 6, 1060-1065 (1991).

20. M. R. Nassiri, S. R. Turk, G. M. Birch, L. A. Coleman, J. L. Hudson, J.S. Pudlo, L. B. Townsend, and J. C. Drach," "Activity of acyclic halogenated tubercidine analogs against human cytomegalovirus and in uninfected cells," Antiviral. Res., 16, 135-150 (1991).

21. R.M. Zuker, K.H. Elstein, R. E. Easterling, and E. J. Massaro, "Flow cytometric analysis of the mechanism of methylmercury cytotoxicity," Am. J. Path., 137, 1187-1197 (1990).

22. K.W. Lanks and J.M. Lehman, "DNA synthesis by L929 cells following Doxorubicin exposure," Cancer Res., 50, 4776-4778 (1990).

23. O.D. Laerum and T. Farsund, "Clinical application of flow cytometry: A review," Cytometry, 2, 1-13 (1981).

24. D.D. Ross, B.W. Thompson, C.C. Joneckis, S. A. Akman, and C.A. Schiffer, "Studies of ara-C metabolism in acute leukemia," Semin. Oncol., 14, 182-191 (1987)

25. M. Tsurusawa, M. Niwa, N. Katano, and T. Fujimoto, "Flow cytometric analysis by bromodeoxyuridine/DNA assay of cell cycle perturbation of methotrexate-treated mouse L1210 leukemia cells," Cancer Res., 48, 4288-4293 (1988).

26. L. L. Wotring and L. R. Roti, "Thioguanine-induced $\mathrm{S}$ and $\mathrm{G}_{2}$ blocks and their significance to the mechanism of cytotoxicity," Cancer Res., 40, 1458-1462 (1980).

Received June 7, 1993

Accepted August 16, 1993 